Mississippi. Almost every river feeding the Mississippi from the West was out of its banks for eight weeks or more. Many rivers were a mile or more out of their banks for several weeks. Many levees collapsed and many threatened to do so for several weeks. Homes along smaller rivers re-flooded as many as seven and eight times. People who never were flooded remained out of their homes for several weeks because of threatened levee breaches.

Farm crop damage was estimated in the billions of dollars. For many, an entire season's crop was lost. Fortunately, 1994 produced almost ideal crop conditions.

\section{Role of the American Red Cross}

The American Red Cross (ARC) participated in this disaster as they do in all disasters. Since 1905, the ARC has been charged by Congress with responding to America's disasters. For this flood, three headquarters were established by the $\mathrm{ARC}$ to respond to the floods: Bettendorf, Iowa; St. Louis, Missouri; and Kansas City, Kansas. Some 250 ARC Chapters were affected. It was estimated that more than 60,000 families were impacted by the floods. More than 28,000 families were served by the Red Cross.

My experience was in Iowa in July and August and in St. Louis in December and January. In Iowa, it began as service to families in about two dozen counties in Iowa and Illinois. Eventually, all 99 counties in Iowa, one county in South Dakota, and 12 counties in Illinois were served from the Bettendorf, Iowa ARG headquarters.

The Mississippi River crested in Bettendorf 15 feet above flood stage on 09 July 1993, and remained above flood stage until late in August. Many rivers feeding the Mississippi crested on repeated occasions. The Red Cross provided family assistance, physical health, and mental health services throughout the affected areas.

\section{Differences from Other Disasters}

Differences between the Mississippi Floods and other disasters were many. My experience spans more than 30 disasters; including hurricanes, tropical storms, coastal storms, a hail storm, a gas explosion, tornadoes, and many flash floods. Most other disasters come and go, and recovery can begin.

However, the Mississippi Floods continued for many weeks. Water stood in most areas continually. In other areas, the water left, recovery began, water returned, left again, perhaps recovery again began, and then water returned. Still other flooding was caused by levee collapses. Additional water threatened the collapse of levees, yet never flooded.

Part of the Red Cross's damage assessment is based on the height of water in homes. Minor damage is at one level; major damage at another. These standards are based on relatively quickly receding waters. In these floods, minor damage became major because of the lingering waters.

The delays in recovery were obvious. When jobs were lost because of the flooding, there was almost nothing to do for many long weeks. Security of property continually concerned victims. Evaluation of disaster needs was suspended for weeks, awaiting receding waters.

\section{Emotional Response}

The Mississippi Floods caused emotional responses both alike and different from other disasters. Response was similar in terms of the many stresses created by abnormal conditions. Also alike were the post-traumatic stress responses
(PTSR) suffered by many victims, dictating interventions in an attempt to avoid the possible development of post-traumatic stress disorder (PTSD). Further similarities included all the problems and responses dictated by any disruption of usual daily routines.

Differences in emotional responses included the "waiting for the other shoe to fall" by those whose homes were reflooded, or whose homes were under the threat of failing levees for several weeks, or people having absolutely nothing to do to help themselves for weeks on end, or working many long hours sandbagging to protect property only to have the efforts fail.

I returned to the flooded areas in December to assist Red Cross workers who were finding that families were unable to assist themselves in recovery because of the belief that Spring would bring the same series of rains and cause the same problems. Discouragement and depression in victims were well beyond what experienced Red Cross workers had found in past disasters.

A particular problem for families was the "government buy-out system" and its establishment during recovery from these floods. Whole towns were being considered for movement to higher ground. The decision date for the buyout was delayed several times. Hopes for recovery were put on hold, and then postponed again and again. After the government decision was made, each family had to decide whether to accept the buy-out or not.

The Great Mississippi Floods of 1993 offered many similarities to and differences from other disasters. The extensiveness and severity of these floods increased the complications for the victims and resulted in more complex interventions for those involved as workers.

\title{
Portraits of Survival: A 20-year Follow-up of the Children of Buffalo Creek
}

\section{Richard G. Homig, MD, ${ }^{1}$ Mary C. Grace, MEd, ${ }^{2,3}$ MS, JacobD. Lindy, MD, ${ }^{2}$ C. Janet Neuman, MD, ${ }^{2}$ James L Titchener, MD ${ }^{2}$}

\footnotetext{
From the University of Cincinnati, Cincinnati, Ohio USA

1. Assistant Clinical Professor of Psychiatry, University of Cincinnati, College of Medicine; Chair, Buffalo Creek Study Group, Cincinnati Psychoanalytic Institute, Cincinnati, Ohio USA 2. Cincinnati Psychoanalytic Institute
}

and the Department of Psychiatry, University of Cincinnati, College of Medicine.

3. Co-Director of the University of Cincinnati Traumatic Stress Study Center, and research consultant to the Cincinnati Psychoanalytic Institute. This project was supported by the Research Fund of the Cincinnati Psychoanalytic Institute.
This is an abstract of an offprint from The Psychoanalytic Study of the Child, 1993, volume 48. The offprint was edited by Albert J. Solnit, Peter B. Neubauer, Samuel Abrams, and A. Scott Dowling for the Yale University Press. In its current form, editing was done by the Editor. 
Research supported in part by National Institute of Mental Health, Grant no. MH42644, B.L. Green, Principal Investigator

This study is a follow-up of the children of Buffalo Creek "hollow" who survived the collapse of a dam and a flood in 1972. It was conceived as a complement to the $1988 \mathrm{NlMH}$-funded follow-up investigation of the children of Buffalo Creek conducted by the University of Cincinnati Traumatic Stress Study Center. That 1988 study utilized standardized methodology to assess levels of psychopathology present among those who were children at the time of the 1972 flood. Among the original child subjects, results demonstrated that the rates of both post-traumatic stress disorder (PTSD) and levels of other psychopathology had sharply declined as the children moved to adulthood. Several questions remained unanswered: the longterm meaning which the flood had in the survivors' lives, and its impact on their adaptation as they progressed through the subsequent stages of emotional development. For these reasons, we, as psychoanalytic investigators who had been members of the original clinical assessment team, planned interviews of child and adolescent survivors as a follow-up to our interviews in 1974. Our particular focus was on meaning and adaptation. Details of these studies may be found in the full paper referenced above. Only the discussion of the four cases examined in depth is reprinted herein.

\section{Methods}

Our method was to further elucidate the flood's impact on subsequent adaptation by a more intensive review of the interviews with a number of subjects for whom we had access to the 1974 child or adolescent diagnostic studies. For each subject, we attempted to categorize, on the basis of the 1974 study, the coping style that was then evident and which appeared to have arisen or been reinforced in response to the flood trauma. When possible, the subject's immediate patterns before and after the flood were compared. Next, we turned to our 1990 interview to explore to what extent the adaptive pattern had persisted or changed as the person moved from childhood and adolescence into their adulthood. We also attempted to explore to what extent the flood-related adaptive pattern was limiting or enhancing overall adult development and to what extent the particular pattern appeared fragile or resilient in the event of new pressures. Finally, by examining our findings against the backdrop of those of the University of Cincinnati Study, we explored the question of what factors within the individual or family might have favored the emergence and persistence of a person's particular pattern of adaptation and whether that particular pattern seemed to mitigate or exacerbate the subsequent persistence of post-traumatic stress disorder (PTSD) or other emotional symptoms.

\section{Findings and Discussion}

As we trace the fate of the flood-related coping responses recognized in our 1974 explorations as these responses consolidate into more enduring patterns of adaptation and perhaps even stable character traits, we can begin to discern a spectrum of "adaptational possibilities." The particular way in which the individual's coping response to the trauma consolidates or does not consolidate appears to influence the ultimate resiliency or rigidity of the adult personality, the responses to subsequent trauma, and the sense of meaning or purpose derived from life. The failure to elaborate stable, trauma-related, adaptive patterns would appear to leave the individual vulnerable to subsequent chronic Post-Traumatic Stress Disorder (PTSD).

From another perspective, the absence of Post-Traumatic Stress Disorder (PTSD) at long-term follow-up, far from indicating that the trauma did not have a significant lasting impact, may rather imply that highly significant and idiosyncratic effects need be sought, not in the review of symptoms, but through exploration of the enduring patterns of adaptation and their origins.

For one of the victims (Helen), the trauma appears to have been largely digested. Her "death dream" suggested still active remnants, but, as observed, these were well-contained. What is more striking is her overall self-confidence, decisiveness, and resiliency played-out against a background of trust that people will and do provide and protect in times of exigency. For Helen, the experience of the flood, although having left clear evidence of its traumatic impact at the time of the 1972 interview, appears ultimately to have presented an opportunity for consolidating adaptive traits of compensation through industry and loculating negative affect as well as to have reinforced the positive narcissism derived from feelings of being loved and well-protected by her family.

At the other extreme from Helen on our spectrum is Rose, who evidenced no effective coping responses to the flood trauma either in 1972 or in the followup in 1992. Indeed, of the four subjects, Rose was the only one who had significant residual PTSD symptomatology in the University of Cincinnati 1988 study. Unlike Helen, Rose felt totally unprotected at the time of the flood. Family functioning appeared marginal before the flood, and during the flood her mother fell, was trapped, and required rescuing. In both 1972 and 1990 assessments, there were persistent themes of regression, interrupted nurturance, and anxious hovering, all a seeming perpetuation of the traumatic state itself. Dramatic in Rose's 1990 drawing is her depiction of herself as beneath the water level of the flood, the position occupied by her mother in her 1972 description.

Intermediate stations in our adaptive spectrum are occupied by Henry and Martha. For Henry, the most prominent theme emerging in both 1972 and 1990 assessments was his observation of and identification with his father's response to the flood, both at the time and in the ensuing years. Like his father, he copes by assuming the mantle of male responsibility as it was presented to him. This cloak weighs heavily upon him and imposes burdens of anxiety, depression, and restriction of choice, but he also gains through it a sense of pride, strength, and fulfillment through his ability to assume his station in the multigenerational male tradition. Subsequent traumatic events, of which there are many, are borne in a similar spirit which further reflects this sense of endurance and community, as evidenced by his response to the many strikes and layoffs he has weathered.

For Martha, such a sense of evident purpose and historical continuity is lacking in the presence of an even more rigid character structure. Interviewers were struck by her compulsivity, which 
seemingly represents a further ossification of the "being a hard worker" mechanism that allowed her to push away the horrors and the depression after the flood. In her memories of the event, she is a caretaker guarding the family. This trait too only solidifies, as she now worries over her parents, her husband, and sometimes his relatives. Anxiety is poorly contained and death imagery is ever present in her dreams. Martha's watchfulness for the next disaster assumes near-psychotic proportions in her visions and premonitions, which seem clearly to recapitulate fragments of the flood experience. By and large, however, the extreme rigidity does safeguard the integrity of Martha's personality, with no overt breakdowns and only occasional breakthroughs of more intense anxiety and depression. Of note is Martha's eagerness to talk to the interviewers about the flood and the freshness of the associated affect. Her unfortunate guilt for years has kept her isolated from other family members during their frequent discussions of the flood, and perhaps, thereby precluded her potential for better integrating the experience.

For all four of these survivors, the family's response to the flood and its aftermath as reflected in their 1990 narrative accounts, appear closely tied to the evolution of the adaptive patterns which subsequently emerged. Helen felt protected; she now feels trusting and secure. Henry watched his father, both his grief and his determination, and he identified. Martha's parents were remote; she was the look-out then and still is. Rose's family nearly drowned, and now she barely treads water. These findings would seem to correlate with earlier Buffalo Creek studies that demonstrated psychopathology in the children to be significantly related to parental psychopathology (Gleser et al, 1981).

In addition, we might consider viewing our subjects' 1990 descriptions of their family's 1972 flood responses as "early memories" in the clinical sense. From this perspective, these memories as well as the entire 90 -minute interviews from which they are drawn, would be seen as condensations, the unraveling of which might reveal rich information about the children's experience of their family throughout their early development and the internalizations that took place. We might even wonder how often a family's response to trauma as experienced and later remembered might serve as a "psychodynamic snapshot" which captures crucial aspects of the family's influence on the child's development and internalizations. Further elucidation of the significance of these memories of the family's trauma response and of the other "clinical impressions" gleaned from our interviews would require a much more intense, psychoanalytically informed investigation than was possible within the scope of this study.

A final note in our considerations of the evolution of our subjects' coping responses into stable character structures: all of the subjects that we have described were adolescents at the time of the flood (except for Rose who was 10 years old). We might question whether the adolescent period of development is a particularly sensitive time for such transformation from coping response to character structure. Such questions are consistent with Peter Blos's observations that the central developmental task of the late adolescent period is character consolidation, which includes the automatization of idiosyncratic ways of dealing with stress (1962, p. 129). Blos points out not only that the role of trauma in character formation is central, but also that it is important to look beyond post-traumatic symptoms to post-traumatic meaning:

A character trait which forms slowly at the end of adolescence owes its special quality to a fixation on a particular trauma or component of a trauma ... focal traumata furnish a relentless force which propels the young adult towards a certain way of life which he comes to feel as his very own... Remnants of trauma relate the present to a dynamic past and establish that historical continuity in the ego which accounts for a sense of certainty, direction, and harmony between feeling and action (1962, p 134).

Such observations are consistent with our findings in the children of Buffalo Creek.

\section{Acknowledgment}

The authors thank Mela Dee Cunningham, Administrator of the Cincinnati Psychoanalytic Institute, for her invaluable assistance on this project.

\section{Bibliography}

Blos P: On Adolescence. Free Press, New York, 1962 Gleser CC, Green BL, Winget, CN: Quantifying interview data on psychic impairment of disaster survivors. J Nerv Ment Dis 1978;166:209-216.

Gleser CC, Green BL, Winget CN: Prolonged Psy chosocial Effects of Disaster. New York: Academic Press, 1981

Green BL, Korol MS, Grace MC, et al: Children and disaster. J Acad Child Adol Psychiat 1991; 30: $945-951$.
Green BL, Lindy JD, Grace MC, et al: Buffalo Creek survivors in the second decade. Amer J Onthopsychiat 1990;60:40-54.

Lyons JA: Post-traumatic stress disorder in children and adolescents. Developmental and Behavioral Pediatrics 1990;8:349-356.

Pynoos RS: Time and trauma. Psychoanal Study Child 1984;39:633-665.

Pynoos RS: Psychic-trauma in children and adolescents. Psychiat Clin North America 1985;8:815-835.
Terr LL: Too Scared to Cry. New York: Harper \& Row. 1990 Terr LL: Childhood traumas. Amer J Psychiat 1991;148:10-20.

Titchener JL, Kapp FT: Family and character change at Buffalo Creek. Amer J Psychiat 1976;133: 295-299.

Titchener JL, Kapp FT, Winget CN: The Buffalo Creek syndrome. In: Emergency and Disaster Management. Bowie, Maryland: Charles Press Publishers, 1976.

\section{The 1988 Spitak Earthquake in Armenia: Implementation of a Mental Health Program and Clinical Observations}

Armen Goenjian, $M D$

Visiting Associate Professor of Psychiatry, University of California-Los Angeles
School of Medicine, Los Angeles, California; Medical Director, Adult and Geriatric Psychiatry, Pacific Hospital, Long Beach, California USA
This presentation described an international mental health relief program for children and adults that was imple 